\title{
Protective effect of metronidazole on uncoupling mitochondrial oxidative phosphorylation induced by NSAID: a new mechanism
}

A Z A Leite, A M Sipahi, A O M C Damião, A M M Coelho, A T Garcez, M C C Machado, C A Buchpiguel, F P Lopasso, M L Lordello, C L O Agostinho, A A Laudanna

\begin{abstract}
Background-The pathogenesis of nonsteroidal anti-inflammatory drug (NSAID) enteropathy is complex. It involves uncoupling of mitochondrial oxidative phosphorylation which alters the intercellular junction and increases intestinal permeability with consequent intestinal damage. Metronidazole diminishes the inflammation induced by indomethacin but the mechanisms remain speculative. A direct effect on luminal bacteria has traditionally been thought to account for the protective effect of metronidazole. However, a protective effect of metronidazole on mitochondrial oxidative phosphorylation has never been tested.
\end{abstract}

Aims-To assess the protective effect of metronidazole on mitochondrial uncoupling induced by indomethacin and also on the increased intestinal permeability and macroscopic damage.

Material and methods-The protective effect of metronidazole was evaluated in rats given indomethacin; a macroscopic score was devised to quantify intestinal lesions, and intestinal permeability was measured by means of ${ }^{51} \mathrm{Cr}$-ethylenediaminetetraacetic acid. The protective effect of metronidazole against mitochondrial uncoupling induced by indomethacin was assessed using isolated coupled rat liver mitochondria obtained from rats pretreated with metronidazole or saline.

Results-Metronidazole significantly reduced the macroscopic intestinal damage and increase in intestinal permeability induced by indomethacin; furthermore, at the mitochondrial level, it significantly reduced the increase in oxygen consumption in state 4 induced by indomethacin and caused less reduction of the respiratory control rate.

Conclusion-Our study confirmed the beneficial effects of metronidazole on intestinal damage and intestinal permeability, and demonstrated, for the first time, a direct protective effect of metronidazole on uncoupling of mitochondrial oxidative phosphorylation caused by NSAIDs.

(Gut 2001;48:163-167)

Keywords: uncoupling agents; intestinal permeability; enteropathy; non-steroidal anti-inflammatory drugs; metronidazole; indomethacin; rats
Non-steroidal anti-inflammatory drugs (NSAIDs) have been used widely because of their analgesic, anti-inflammatory, and antipyretic properties. The main concern with these drugs is the frequency and severity of their digestive side effects, ${ }^{1}$ involving the entire gastrointestinal tract. ${ }^{23}$ Scintilograms suggest small intestinal inflammation in $42 \%$ of patients taking NSAIDs, faecal calprotectin levels suggest inflammation in $44 \%,{ }^{4}$ but when faecal excretion of ${ }^{111}$ In-labelled leucocytes was used as a measure of inflammation, up to $67 \%^{5-9}$ of patients had an enteropathy. Similarly, intestinal lesions detected by enteroscopy $^{10}$ have been described in $66 \%$ of patients and in a postmortem study, the prevalence of non-specific intestinal ulceration was $13.5 \%$ in those who had consumed NSAIDs for a long period of time (six months or more). ${ }^{11}$ The intestinal lesions caused by NSAIDs may lead to chronic bleeding, ${ }^{12-14}$ protein $\operatorname{loss}^{8}$ and, occasionally, strictures. ${ }^{15-20}$ There have also been reports of NSAIDs causing enteritis and/or colitis, ${ }^{21-27}$ decreased xylose absorption, ${ }^{28}$ and increased incidence of perforation, ${ }^{29}$ and also associations with diverticulitis, ${ }^{30} 31$ appendicitis, ${ }^{32}$ internal fistulas, ${ }^{33}$ and relapse of inflammatory bowel disease. ${ }^{34-36}$

The pathogenesis of NSAID enteropathy is complex and there are many uncertainties. Somasumdaram and colleagues ${ }^{37}$ suggest that there are three crucial steps in the pathogenesis. The first step involves specific biochemical damage of mitochondria, ${ }^{38-40}$ uncoupling the oxidative phosphorylation reaction, during drug absorption and/or after biliary excretion (enterohepatic circulation). ${ }^{41-45}$ Electron microscopic studies show vacuolisation and ballooning of mitochondria within an hour of indomethacin administration which is highly characteristic of uncoupling of oxidative phosphorylation. ${ }^{46}$ The consequence of uncoupling is diminished cellular ATP, which alters the intercellular junction, increases intestinal permeability, and releases calcium into cytosol which in turn causes secondary biochemical damage..$^{97-50}$ NSAID inhibition of cyclooxygenase appears not to be involved in this

Abbreviations used in this paper: NSAIDs, non-steroidal anti-inflammatory drugs; DMSO, dimethyl sulphoxide; ${ }^{51} \mathrm{Cr}$-EDTA, ${ }^{51} \mathrm{Cr}$-ethylenediaminetetraacetic acid; EGTA, ethylene glycol-bis ( $\beta$-aminoethyl ether)- $N, N, N^{\prime}, N^{\prime}$-tetraacetic acid; HEPES, $N$-(2-hydroxyethyl)piperazine- $N$ (2-ethanesulphonic acid); RCR, respiratory control rate. 
framework. ${ }^{51} 52$ In the context of NSAID induced enteropathy, increased intestinal permeability (transitional stage) will convert the biochemical damage into a tissue reaction. In the second step, mucosa is exposed to digestive enzymes and bile, ${ }^{47} 48$ and bacteria ${ }^{53-58}$ and their products, which appear to be the main neutrophil chemoattractants. ${ }^{59-61}$ When phagocytosis takes place, neutrophils may cause tissue damage by free radical ${ }^{62}{ }^{63}$ production and lysosomal release. The role of bacteria has been inferred by almost universal findings which have demonstrated that indomethacin provokes very few macroscopic lesions in germ free animals ${ }^{5657}$ and in those pretreated with antibiotics..$^{53} 5564$

Metronidazole seems to diminish most parameters of inflammation induced by indomethacin; nevertheless, the mechanism by which the drug protects the mucosa and attenuates inflammation remains only speculative. Data from the medical literature suggest that metronidazole may have a direct effect on luminal bacteria attenuating enhanced mucosal permeability caused by indomethacin and reducing massive bacterial translocation into the mesenteric lymph nodes, liver, and spleen, ${ }^{65}$ rather than a cytoprotective role. In this context, this drug should protect only during the second step, where endogenous bacteria are involved, although in some studies metronidazole protected against the increase in intestinal permeability induced by NSAIDs, indicating a direct effect of metronidazole at the beginning of intestinal damage. Bjarnason and colleagues ${ }^{64}$ reported that intestinal inflammation and blood loss were significantly reduced with metronidazole; nevertheless they were unable to show a significant difference in intestinal permeability after treatment with metronidazole. However, this work included patients who had been taking NSAIDs for at least six months. Accordingly, Yamada and colleagues, ${ }^{65}$ in an experimental model, found that metronidazole did not reduce mucosal permeability at one day following injection of indomethacin but mucosal permeability was reduced after 48 hours, and concluded that metronidazole probably had a direct effect on the late stage (second step) involving luminal bacteria. In contrast, Davies and colleagues, ${ }^{66}$ in humans, showed that coadministration of metronidazole for a short period of time successfully prevented the indomethacin induced change in intestinal permeability. Similarly, Davies and Jamali, ${ }^{67}$ in rats, demonstrated that metronidazole reversed the increased intestinal permeability caused by NSAIDs but attributed this finding to the potential free radical scavenger action of metronidazole. Thus the exact point(s) where metronidazole protects small intestinal injury is(are) not known. The finding of precocious metronidazole protection is important because it would indicate a direct effect of the drug at the beginning of NSAID injury. To test this hypothesis, we have studied the protective effect of metronidazole on macroscopic damage and intestinal permeability induced by indomethacin in rats and in isolated coupled mitochondria in an attempt to determine the mechanism underlying metronidazole protection of NSAID induced small intestinal injury.

\section{Material and methods}

Male Wistar rats (250-350 g) were housed in individually metabolic cages. Rats were given water and standard laboratory rat chow ad libitum. Eighty rats were divided into three groups: vehicle (water) control group $(n=27)$, indomethacin group $(\mathrm{n}=26)$, and indomethacin in combination with metronidazole group $(n=27)$.

Intestinal inflammation was induced by administration of a single dose of indomethacin $(7.5 \mathrm{mg} / \mathrm{kg})$ by gavage. The drug was initially dissolved in dimethyl sulphoxide (DMSO) and diluted so that the final concentration of DMSO was $5 \%(\mathrm{v} / \mathrm{v})$ and adjusted to $\mathrm{pH} 7.4$, after which they had free access to standard rat food and water.

Metronidazole was given by gavage in three divided doses $(60 \mathrm{mg} / \mathrm{kg} /$ dose - total dose 180 $\mathrm{mg} / \mathrm{kg}$ ), 12 hours apart, beginning at the same time as indomethacin.

Intestinal permeability was assessed using urinary excretion of ${ }^{51} \mathrm{Cr}$-ethylenediaminetetraacetic acid $\left({ }^{51} \mathrm{Cr}-\mathrm{EDTA}\right)$, as previously described, ${ }^{48}$ after oral administration. Animals received either indomethacin and/or metronidazole as described above. Rats were given $5 \mu \mathrm{Ci}$ of ${ }^{51} \mathrm{Cr}$-EDTA in $0.5 \mathrm{ml}$ of distilled water by gavage, followed by $5 \mathrm{ml}$ of water. Animals were then placed in individual metabolic cages for five hours for collection of urine and had free access to tap water and food. Rats were sacrificed by lethal injection $(50 \mathrm{mg}$ ) of ketamine (Ketalar) and laparotomy was performed and the bladder emptied by puncture. Total five hour radioactivity excreted in urine was determined together with standards in a gamma counter for two minutes. Data were expressed as fractional excretion of the radioactive marker. The small intestine was then gently removed, the intestinal mucosa was exposed by cutting through the contra mesenteric side, laid out on a piece of cork, and dried with Evan's blue to improve assessment of macroscopic score, 29 hours after giving the drugs, using a sterostatic microscope (25-50 times). A macroscopic score was devised to quantify intestinal lesions: total number of mucosal ulcers with: (a) $<1 \mathrm{~mm}$; (b) $\geqslant 1$ and $<3$ $\mathrm{mm}$; (c) $\geqslant 3$ and $<5 \mathrm{~mm}$; (d) $\geqslant 5$ and $<10 \mathrm{~mm}$; and (e) $\geqslant 10 \mathrm{~mm}$, multiplied by $1,3,5,10$, and 20 , respectively. Total score was the sum of the values obtained in each item. A separate group of male Wistar rats $(n=18)$ weighing $250 \mathrm{~g}$ was used to determine the effect of indomethacin on mitochondria in vitro, and was subdivided into two groups: one received a single dose of $100 \mathrm{mg}$ of metronidazole intraperitoneally and the other saline, both five hours before liver extraction and mitochondrial isolation.

Preparation of coupled mitochondria was as previously described ${ }^{68}$ from animals sacrificed by decapitation. The liver was rapidly dissected and placed in ice cold homogenising solution No 1 (280 mM sucrose, $0.1 \mathrm{mM}$ EGTA (ethylene glycol-bis( $\beta$-aminoethyl ether)- $N, N, N^{\top}, N^{\top}$ tetraacetic acid), $2 \mathrm{mM}$ HEPES $(\mathrm{N}-(2-$ hydroxyethyl)piperazine- $N$-(2-ethanesulphonic 
acid)), $5 \mathrm{mg} / \mathrm{ml}$ bovine serum albumin at $\mathrm{pH}$ 7.4 ), cut finely into approximately $1 \mathrm{~cm}$ pieces with scissors, and washed twice with homogenising solution to remove excess blood. The liver was then suspended in $50 \mathrm{ml}$ of the same homogenising solution and homogenised in a Potter-Elvjehm homogeniser by six strokes with a rotation Teflon pestle. The homogenate was then centrifuged at $900 \mathrm{~g}$ for 10 minutes to remove excess blood, nuclei, and cell debris. The supernatant was centrifuged at $10000 \mathrm{~g}$ for another 10 minutes, after which the pellet was removed and resuspended in $10 \mathrm{ml}$ of homogenising solution No 2 ( $280 \mathrm{mM}$ sucrose, $2 \mathrm{mM}$ HEPES, pH 7.4). The isolation procedure took approximately 45 minutes with the homogenate being kept at $0-4^{\circ} \mathrm{C}$. Mitochondrial protein concentration was determined using Lowry's method. ${ }^{69}$

Oxygen consumption was polarographically measured $^{70}$ using a Clarke type oxygen electrode (Clark; Yellow Springs Instruments Co., Yellow Springs, Ohio, USA) as described by Chance and Williams. ${ }^{71}$ The electrode was fitted into a thermostatic Plexiglas chamber containing $1.55 \mathrm{ml}$ of oxygen electrode buffer (120 $\mathrm{mM} \mathrm{KCl,} 5 \mathrm{mM}$ de Tris, $1 \mathrm{mM}$ EGTA, bovine serum albumin $0.1 \%, \mathrm{pH} 7.4$ ). A small amount $(100 \mu \mathrm{l})$ of the mitochondrial preparation, $35 \mu \mathrm{l}$ of potassium succinate $(10 \mathrm{mM}), 20 \mu \mathrm{l}$ of ADP (504 $\mathrm{mM}$ ), and $0-100 \mu \mathrm{l}$ of indomethacin (to a final concentration of $0-140 \mu \mathrm{mol} / \mathrm{mg}$ protein) were introduced through a small hole in the chamber lid. The experiments were carried out at $30^{\circ} \mathrm{C}$ with continuous magnetic stirring. Oxygen consumption was measured after five minutes and monitored for approximately two minutes for each experiment. Three to six experiments were performed at each indomethacin concentration for each rat. Indomethacin was dissolved in DMSO (final concentration of DMSO in the chamber never exceeded $0.3 \% \mathrm{v} / \mathrm{v}$ ). Control experiments used distilled water only as in a prior experiment conducted in our laboratory we verified that DMSO, in concentrations up to 10 times higher than the maximum used in the present in vitro experiments, was similar to water in terms of oxygen consumption.

STATISTICAL ANALYSIS

Results are expressed as mean (SEM). Statistical differences in macroscopic scores and intestinal permeability among groups were assessed using non-parametric tests (KruskalWallis and Dunn). Statistical differences in oxygen consumption between DMSO and water, and controls in the metronidazole and water groups were assessed by a nonparametric test (Mann-Whitney). Statistical differences in oxygen consumption between groups were assessed by regression analysis.

\section{Results}

MACROSCOPIC DAMAGE

Figure 1 shows that the values for macroscopic scores were significantly different among the three groups: control, indomethacin, and indomethacin plus metronidazole groups $(\mathrm{p}<0.0001)$. Using a discriminatory test it was

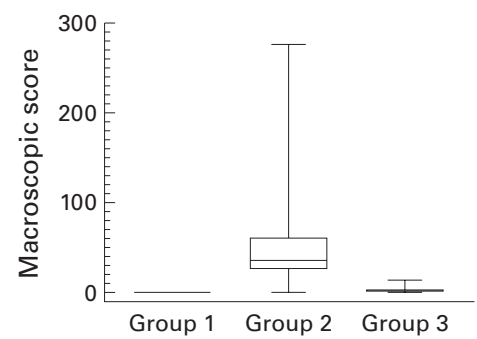

Figure 1 Box and whisker plot showing median macroscopic score (horizontal line), 25th and 75th centiles (box), and range (whiskers) in the control (group 1, $n=10$ ), indomethacin (group $2, n=10$ ), and indomethacin plus metronidazole (group 3, $n=10$ ) groups. Group $1 v$ group $2, p<0.0001$; group $1 v$ group $3, N S$; group $2 v$ group $3, p<0.001$.

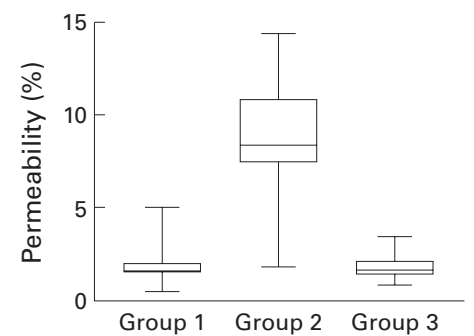

Figure 2 Box and whisker plot showing median intestinal permeability (horizontal line), 25th and 75th centiles (box), and range (whiskers) in the control (group 1, $n=17$ ), indomethacin (group 2, $n=16$ ), and indomethacin plus metronidazole (group 3, $n=17$ ) groups. Values are percentage of ${ }^{51} \mathrm{Cr}$-EDTA excreted in five hour urine. Group 1 v group $2, p<0.05$; group 1 v group $3, N S$; group $2 v$ group $3, p<0.05$.

possible to see that macroscopic scores were significantly lower when metronidazole was administered together with indomethacin compared with indomethacin alone (indomethacin with metronidazole 3.3 (1.4) $v$ indomethacin 63.6 (25.9); p<0.05) and was not different from the control group (indomethacin with metronidazole 3.3 (1.4) $v$ control 0 ; NS)

\section{INTESTINAL PERMEABILITY}

Intestinal permeability, as assessed by ${ }^{51} \mathrm{Cr}-$ EDTA, was significantly different among the three groups $(p<0.0001)$ (fig 2$)$. Intestinal permeability was significantly increased after indomethacin (controls $2.0 \quad(0.3) \% \quad v \quad$ indomethacin $8.9(0.8) \% ; \mathrm{p}<0.0001)$. When metronidazole was added, there was no significant difference compared with controls (indomethacin with metronidazole $1.9(0.2) \%$; NS), but it was significantly different from indomethacin alone $(\mathrm{p}<0.05)$.

\section{OXYGEN CONSUMPTION}

The increase in oxygen consumption induced by indomethacin was significantly lower in the metronidazole group $(p=0.046)$ (fig 3$)$; in addition, there was a less pronounced reduction in respiratory control rate (RCR) $(\mathrm{p}=0.035)$ (fig 4) compared with the metronidazole group. There was no significant difference in oxygen consumption in state 4 (S4) (control 48.2 (2.3) $v$ metronidazole 40.1 (3.1); $\mathrm{p}=0.16)$ or RCR (control 3.1 (0.1) v metronidazole $2.8(0.1) ; \mathrm{p}=0.29)$ between both groups before administration of indomethacin. These data are consistent with the results of Aicardi 


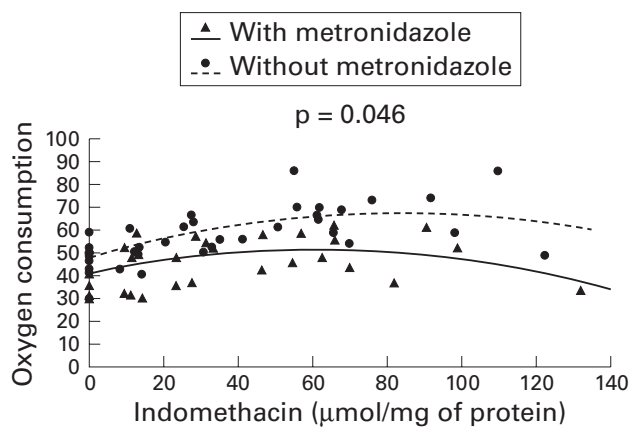

Figure 3 Regression analysis of the effects of metronidazole on oxygen consumption in the basal state (S4) (values are umol of oxygen/mg of protein).

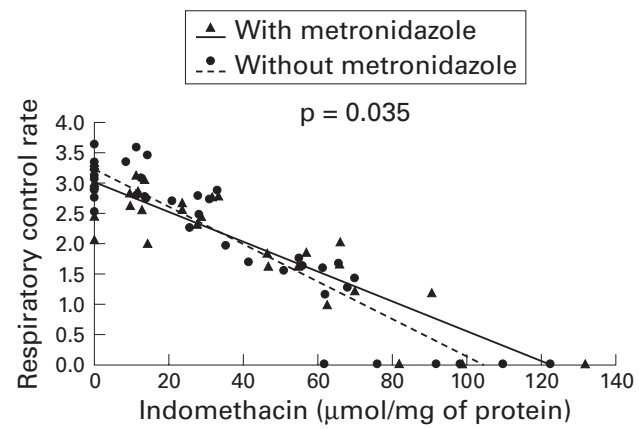

Figure 4 Regression analysis of the effects of metronidazole on respiratory control rate (RCR). Relation between consumption of oxygen with $A D P(S 3)$ and after it has been consumed (S4).

and Solaini ${ }^{72}$ which showed no effect of metronidazole alone on oxygen consumption.

\section{Discussion}

NSAID induced enteropathy includes three distinct phases ${ }^{37}$ : an early phase (first step) involving uncoupling of mitochondrial oxidative phosphorylation followed by a transitional stage characterised by increased intestinal permeability, and a late phase (second step) when the intestinal mucosa is exposed to aggressive agents (for example, bacteria and their products) that promote the release of inflammatory mediators with ensuing additional increase in intestinal permeability and finally, tissue damage.

The protective effect of metronidazole on NSAID induced enteropathy has been studied recently. ${ }^{64-67}$ However, the mechanisms by which metronidazole exerts this protection are not completely understood. Yamada and colleagues ${ }^{65}$ in a rat model of intestinal inflammation (indomethacin), suggested that the protective effect of metronidazole was due to its antibacterial action. However, Davies and Jamali ${ }^{67}$ using a similar experimental model, demonstrated that metronidazole protected against increased intestinal permeability induced by indomethacin at an early stage (12 hours after indomethacin) and concluded that metronidazole directly interfered at a time when participation of luminal bacteria was less evident. ${ }^{37}$ Moreover, Davies and Jamali $^{67}$ showed that the protective effect of metronidazole was dose dependent. Methodological differences between these studies ${ }^{65}$ probably explain the discrepancies.
Our results confirm previous work ${ }^{65}{ }^{67}$ where metronidazole was associated with a significant reduction in macroscopic intestinal damage induced by NSAIDs (fig 1). Also, metronidazole prevented NSAID induced permeability change (fig 2) approximately 24 hours after administration of indomethacin. In common with Davies and Jamali, ${ }^{67}$ we also noticed a dose dependent relationship in metronidazole protection (data not shown). The intestinal damage induced by indomethacin reaches its maximal after 3-4 days ${ }^{55}$ when luminal bacteria and their products have a place. The protection we observed with metronidazole, about 24 hours after indomethacin, suggests that metronidazole may intervene in an early phase of intestinal injury with little or no influence of luminal offensive agents. Also, a direct effect of metronidazole - and not an antibiotic mediated effect-is corroborated by the recent demonstration that metronidazole minimises indomethacin induced intestinal injury in germ free rats. ${ }^{73}$ Our in vitro studies confirmed this hypothesis. Mitochondrial uncoupling is characterised by increased oxygen consumption in stage 4 (S4) and reduced RCR. Metronidazole significantly reduced the increase in mitochondrial oxygen consumption in stage 4 (S4) (fig 3 ) induced by indomethacin and caused less reduction in RCR (fig 4). Both features are related to a direct protective effect of metronidazole on uncoupling of mitochondrial oxidative phosphorylation caused by NSAID.

In the present work, we have described, for the first time, a new effect of metronidazole: its direct effect on mitochondrial oxidative phosphorylation and, indirectly, on the intercellular junction. Thus the protective effect of metronidazole against NSAID induced increased intestinal permeability may include an action on mitochondrial uncoupling. Our work uncovers new perspectives in the study of drugs that can directly interfere with mitochondrial uncoupling and eventually protect against NSAID induced enteropathy.

1 Geis GS, Stead H, Wallemark C-B E, et al. Prevalence of mucosal lesions in the stomach and duodenum due to chronic use of NSAID in patients with rheumatoid arthritis or osteoarthritis, and interim report on prevention by misoprostol of diclofenac associated lesions. $\mathcal{F}$ Rheumatol 1991;18(suppl 28):11-14.

2 Collins, AJ, Davies J, Dixon SA. Contrasting presentation and findings between patients with rheumatic complaints taking nonsteroidal anti-inflammatoty drugs and a general population referred for endoscopy. $\mathrm{Br} f$ Rheumatol 1986;25:50-3.

3 Langman MJ. Epidemiological evidence on the association between peptic ulceration and antiinflammatory drug use. between peptic ulceration and antinflammatory
Gastroenterology 1989;96(2 pt 2 suppl):640-6.

4 Tibble JA, Sigthorsson G, Foster R, et al. High prevalence of NSAID enteropathy as shown by a simple faecal test. Gut NSAID enteropa

5 Bjarnason I, Zanelli G, Smith T, et al. Nonsteroidal antiinflammatory drug-induced intestinal inflammation in humans. Gastroenterology 1987;93:480-9.

6 Rooney PJ, Jenkins RT, Smith KM, et al. 111-Indiumlabelled polymorphonuclear leucocyte scans in rheumatoid arthritis - an important clinical cause of false positive results. Br ₹ Rheumatol 1986;25:167-70.

7 Segal AW, Isenberg DA, Hajirousou V, et al. Preliminary evidence for gut involvement in the pathogenesis of rheumatoid arthritis? Br F Rheumatol 1986;25:162-6.

8 Bjarnason I, Zanelli G, Prouse P, et al. Blood and protein loss via small intestinal inflammation induced by nonsteroidal anti-inflammatory drugs. Lancet 1987;2:711-14.

9 Bjarnason I, Williams P, So A, et al. Intestinal permeability and inflammation in rheumatoid arthritis: Effects of non-steroidal anti-inflammatory drugs. Lancet 1984;2: 1711-13. 
10 Morris AJ, Madhock R, Sturrock RD, et al. Enteroscopic diagnosis of small bowel ulceration in patients receiving 520 .

11 Allison MC, Howatson AG, Torrance CJ, et al. Gastrointestinal damage associated with the use of nonsteroida anti-inflammatory drugs. N Engl F Med 1992;327:749-54

12 Morris AJ, Wasson LA, Mackenzie JF. Small bowel enteroscopy in undiagnosed gastrointestinal blood loss. Gut 1992 33:887-9.

13 Madhok R, Mackenzie JA, Lee FD, et al. Small bowel ulceration in patients receiving non-steroidal anti-
inflammatory drugs for rheumatoid arthritis. $Q f \mathrm{Med}$ 1986;58:53-8.

14 Collins AJ, Du Toit JA. Upper gastrointestinal findings and faecal occult blood in patients with rheumatic disease taking nonsteroidal anti-inflammatory drugs. Br f Rheumatol 1987;26:295-8.

15 Bjarnason I, Price AB, Zanelli G, et al. Clinicopathological features of nonsteroidal anti-inflammatory drug-induced features of nonsteroidal anti-inflammatory drug-induced
small intestinal strictures. Gastroenterology 1988;94:1070 sma.

16 Bjarnason I, Hayllar J, Macpherson AJ, et al. Side effects of nonsteroidal anti-inflammatory drugs on the small and large intestine in humans. Gastroenterology 1993;104:183247.

17 Huber T, Ruchti C, Halter F. Nonsteroidal antiinfiammatory drug-induced colonic strictures: a case report. Gastroenterology 1991;100:1119-22

18 Johnson F. Recurrent small bowel obstruction associated with piroxicam. BrF Surg 1987;74:654

19 Sukumar L. Recurrent small bowel obstruction associated with piroxicam. Brf Surg 1987;74:186.

20 Hershfield NB. Endoscopic demonstration of non-steroidal anti-infiammatory drug-induced small intestinal strictures. Gastrointest Endosc 1992;38:388-90.

21 Hall RI, Petty AH, Cobden I, et al. Enteritis and colitis associated with mefenamic acid. BMf (Clin Res Ed) 1983;287: 1182 .

22 Banerjee AK. Enteropathy induced by non-steroidal antinflammatory drugs. BMF 1989;298:1539-40.

23 Tanner AR, Raghunath AS. Colonic inflammation and nonsteroidal anti-inflammatory drug administration. Digestion $1988 ; 41: 116-20$

24 Clements D, Williams GT, Rhodes J. Colitis associated with ibuprofen. BMF 1990;301:987

25 Ravi S, Keat AC, Keat EC. Colitis caused by non-steroidal anti-inflammatory drugs. Postgrad Med F 1986;62:773-6.

26 Schwartz HA. Lower gastrointestinal side effect of nonsteroidal antiinflammatory drugs. F Rheumatol 1981;8:952-4.

27 Aabakken L, Osnes M. Non-steroidal anti-inflammatory drug-induced disease in the distal ileum and large bowel. Scand $\mathcal{F}$ Gastroenterol Suppl 1989;163:48-55.

28 Kendall MJ, Nutter S, Hawkins CF. Xylose test: effect of aspirin and indomethacin. BMF 1971;1:533-6.

29 Coutrot S, Roland D, Barbier J, et al Acute perforation of colonic diverticula acsociated with short-term indomethacin. Lancet 1978;2:1055-6.

30 Campbell K, Steele RJ. Non-steroidal anti-inflammatory drugs and complicated diverticular disease: a case control study. Br ₹ Surg 1991;78:190-1.

31 Wilson RG, Smith AN, Macintyre IM. Complications of diverticular disease and nonsteroidal anti-infiammatory drugs: a prospective study. Br F Surg 1990;77:1103-4.

32 Campbell KL, De Beaux AC. Non-steroidal antiinfiammatory drugs and appendicitis in patients aged over 50 years. Br ₹ Surg 1992;79:967-8.

33 Finkelstein JA, Jamieson CG. An association between anti-infiammatory medication and internal pelvic fistulas. Dis Colon Rectum 1987;30:168-70.

34 Kaufmann HJ, Taubin HL. Nonsteroidal anti-inflammatory drugs activate quiescent inflammatory bowel disease. Ann Intern Med 1987;107:513-6.

35 Rampton DS, McNeil NI, Sarner M. Analgesic ingestion and other factors preceding relapse in ulcerative colitis. Gut 1983;24:187-9.

36 Rampton DS, Sladen GE. Relapse of ulcerative proctocolitis during treatment with non-steroidal anti-inflammatory drugs. Postgrad Med $\mathcal{F} 1981 ; 57: 297-9$.

37 Somasumdaram S, Hayllar $\mathrm{H}$, Rafi S, et al The biochemical basis of non-steroidal anti-inflammatory drug-induced damage to the gastrointestinal tract: a review and a hypothesis. Scand $\mathcal{F}$ Gastroenterol 1995;30:289-99.

38 Mingatto FE, Santos AC, Uyemura SA, et al. In vitro interaction of nonsteroidal anti-inflammatory drugs on oxidative phosphorylation of rat kidney mitochondria: respiration and ATP synthesis. Arch Biochem Biophys 1996;334: 303-8

39 Mahmud T, Rafi SS, Scott DL, et al. Nonsteroidal antiinflammatory drugs and uncoupling of mitochondrial oxidative phosphorylation. Arthritis Rheum 1996:39:19982003.

40 Somasundaram S, Rafi S, Jacob M, et al. Intestinal tolerability of nitroxybutyl-flurbiprofen in rats. Gut 1997;40:608 13 .

41 Brune K, Dietzel K, Nürnberg B, et al. Recent insight into the mechanism of gastrointestinal tract ulceration. Scand $\mathcal{F}$ the mechanism of gastrointestinal

42 Wax J, Clinger WA, Varner P, et al. Relationship of the enterohepatic cycle to ulcerogenesis in the rat small bowel with flufenamic acid. Gastroenterology 1970;58:772-80.

43 Bjarnason I, Fehilly B, Smethurst P, et al. Effects of nonsteroidal anti-inflammatory drugs on permeability of the smal intestine in humans. F Rheumatol 1992;19(suppl 36):83-4
44 Bjarnason I, Fehilly B, Smethurst P, et al. Importance of local versus systemic effect of non-steroidal antiinflammatory drugs in increasing small intestinal permeability in man. Gut 1991;32:275-7.

45 Reuter BK, Davies NM, Wallace JL. Nonsteroidal antiinflammatory drug enteropathy in rats: role of permeability, bacteria, and enterohepatic circulation Gastroenterology 1997;112:109-17.

46 Somasumdaram S, Rafi S, Hayllar J, et al. Mitochondrial damage:a possible mechanism of the "topical" phase of NSAID induced injury to the rat intestine. Gut 1997;41: 344-53.

47 Zuccato E, Bertolo C, Colombo L, et al. Indomethacininduced enteropathy: effect of drug regimen on intestinal permeability in rats. Agents Actions 1992;Spec No:C18-21.

48 Bjarnason I, Smethurst P, Levi AJ, et al. Intestinal permeability to ${ }^{51} \mathrm{Cr}$-EDTA in rats with experimentally induced enteropathy. Gut 1985;26:579-85.

49 Aabakken L, Osnes M. ${ }^{51} \mathrm{Cr}$-ethylenediaminetetraacetic acid absortion test. Effects of naproxen, a non-steroidal, antiinflammatory drug. Scand $\mathcal{F}$ Gastroenterol 1990;25:917-24.

50 Jenkins RT, Rooney PJ, Jones DB, et al. Increased intestinal permeability in patients with rheumatoid arthritis: a side
effect of oral nonsteroidal anti-inflammatory drug therapy? Brf Rheumatol 1987;26:103-7.

51 Bjarnason I, Williams P, Smethurst P, et al. Effect of non-steroidal anti-inflammatory drugs and prostaglandins on the permeability of the human small intestine. Gut 1986;27:1292-7.

52 Mahmud T, Somasundaram S, Sigthorsson G, et al. Enantiomers of flubiprofen can distinguish key pathophysiological omers of flubiprofen can distinguish key pathophysiological
steps of NSAID enteropathy in the rat. Gut 1998;43:77582 .

53 Brodie DA, Cook PG, Bauer BJ, et al. Indomethacininduced intestinal lesions in the rat. Toxicol Appl Pharmacol 1970;17:615-24

54 Fang WF, Broughton A, Jacobson ED. Indomethacininduced intestinal inflammation. Am f Dig Dis 1977;22: $749-60$.

55 Kent TH, Cardelli RM, Stamler FW. Small intestinal ulcers and intestinal flora in rats given indomethacin. Am f Pathol 1969;54:237-49.

56 Melarange R, Moore G, Blower PR, et al. A comparison of indomethacin with ibuprofen on gastrointestinal mucosal integrity in conventional and germ-free rats. Aliment Pharmacol Ther 1992;6:67-77.

57 Robert A, Asano T. Resistance of germfree rats to indomethacin-induced intestinal lesions. Prostaglandins 1977; 14:333-41.

58 Satoh H, Guth PH, Grossman MI. Role of bacteria in gastric ulceration produced by indomethacin in the rat: cytoprotective action of antibiotics. Gastroenterology 1983; 84:483-9.

59 Wallace JL. Non-steroidal anti-inflammatory drug gastropathy and cytoprotection: pathogenesis and mechanisms re-examinned. Scand f Gastroenterol Suppl 1992;192:3-8.

60 Bjarnason I, Zanelli G, Stnith T, et al. The pathogenesis and consequence of nonsteroidal anti-inflammatory drug induced small intestinal inflammation. Scand 7 Rheumatol Suppl 1987;64:55-67.

61 Bjarnason I, Macpherson A. The changing gastrointestinal side effect profile of non-steroidal anti-inflammatory drugs. A new approach for the prevention of a new problem. Scand f Gastroenterol Suppl 1989;163:56-64.

62 Weiss SJ. Tissue destruction by neutrophils. $N$ Engl f Med 1989;320:365-76.

63 Malech HL, Gallin JI. Current concepts: immunology. Neutrophils in human disease. N Engl f Med 1987;317:687-94

64 Bjarnason I, Hayllar J, Smethurst P, et al. Metronidazole reduces intestinal inflammation and blood loss in nonsteroidal anti-inflammatory drug induced enteropathy. Gut 1992;33:1204-8.

65 Yamada T, Deitch E, Specian RD, et al. Mechanisms of acute and chronic intestinal inflammation induced by indomethacin. Inflammation 1993;17:641-62.

66 Davies GR, Wilkie ME, Rampton DS. Effects of metronidazole and misoprostol on indomethacin-induced changes in intestinal permeability. Dig Dis Sci 1993;38:417-25.

67 Davies NM, Jamali F. Pharmacological protection of NSAID-induced intestinal permeability in the rat: effect of tempo and metronidazole as potential free radical scarvengers. Hum Exp Toxicol 1997;16:345-9.

68 Schneider WC, Hogeboom GH. Intracellular distribution of enzymes. V. Further studies on the distribution of cytochrome c in rat liver homogenate. If Biol Chem 1950;183:123-8.

69 Lowry OH, Rosebrough NJ, Farr AL, et al. Protein meansurement with the folin phenol reagent. $f$ Biol Chem 1951;193:265-75.

70 Estabrook RW. Mitochondrial respiratory control and the polarographic measurement ADP: O ratios. In: Estabrook RW, Pullman ME, eds. Methods enzymol, vol. 10. New York: Academic $1967: 41-7$

71 Chance B, Williams GR. A simple and rapid assay of oxidative phosphorylation. Nature 1955;175:1120-1.

72 Aicardi G, Solaini G. Effects of niridazole and 5-nitromidazoles on heart mitochondrial respiration. Biochem Pharmacol 1982;31:3703-5.

73 Colpaert SA, Liu Z, Ceuppens J, et al. Comparative study on the in vivo efficacy of metronidazole, aztreonam and amoxycillin/clavulanic acid in the indomethacin model: evidence for immuno-modulatory properties of metronidazole. Gastroenterology 2000;118(suppl 2):A572. 